\title{
ABAT and ALDH6A1, regulated by transcription factor HNF4A, suppress tumorigenic capability in clear cell renal cell carcinoma
}

\author{
Jun Lu ${ }^{1,2,3^{*} \dagger}$, Zhan Chen ${ }^{2 \dagger}$, Hu Zhao ${ }^{1,2,3 \dagger}$, Huiyue Dong ${ }^{1,2,3 \dagger}$, Ling Zhu ${ }^{1,2,3}$, Yi Zhang ${ }^{2}$, Jie Wang ${ }^{2}$, Hehuan Zhu ${ }^{2}$, \\ Qiang Cui ${ }^{2}$, Chuang Qi ${ }^{1}$, Shuiliang Wang ${ }^{1,2,3}$, Shushang Chen ${ }^{3}$ and Jichun Shao ${ }^{4^{*}}$
}

\begin{abstract}
Background: Clear cell renal cell carcinoma (ccRCC) is a malignancy characterized by metabolic reprogramming. ABAT and ALDH6A1 are metabolic enzymes. In this study, we aim to investigate the associations of ABAT and ALDH6A1 with the malignancy of CCRCC cells.

Methods: The gene expression levels of ABAT and ALDH6A1 in CCRCC were analyzed from gene expression microarray datasets and RNA sequencing data. Clinical information was analyzed from The Cancer Genome Atlas (TCGA) data. The distributions of ABAT and ALDH6A1 in CCRCC clinical tissues were screened by reverse transcription-quantitative polymerase chain reaction (RT-QPCR) and immunohistochemical assays. The effect of overexpression of ABAT or ALDH6A1 was measured by detecting the cell viability, migration ability, and the ratio of lactate and nicotinamide adenine dinucleotide phosphate (NADPH). Chromatin immunoprecipitation (ChIP) and luciferase reporter assays were carried out to investigate the transcript regulation of HNF4A in ABAT and ALDH6A1.

Results: Remarkable downregulated ABAT and ALDH6A1 expression levels were observed in CCRCC patients and low expression of ABAT and ALDH6A1 was correlated with poor survival. Overexpression of ABAT or ALDH6A1 significantly attenuated cell proliferation and migration, and impaired lactate production. In ABAT increased ccRCC cells, the ratio of NADPH/NADP + was reduced. Finally, we demonstrated that ABAT and ALDH6A1 were directly regulated by a tumor suppressor, HNF4A.
\end{abstract}

Conclusions: These observations identified HNF4A-regulated low-expressed ABAT and ALDH6A1 as promising diagnostic and prognostic biomarkers for cCRCC.

Keywords: Clear cell renal carcinoma (ccRCC), ABAT, ALDH6A1, HNF4A, Transcription factor

*Correspondence: junlu.heather@xmu.edu.cn; shaoji93@163.com

${ }^{\dagger} J u n$ Lu, Zhan Chen, Hu Zhao and Huiyue Dong have contributed equally to this work

${ }^{1}$ Fujian Provincial Key Laboratory of Transplant Biology, Fuzhou General

Clinical College, Fujian Medical University, Fuzhou 350025, China

${ }^{4}$ Department of Urology, Second Affiliated Hospital of Chengdu

Medical College (China National Nuclear Corporation 416 Hospital), Chengdu 610051, China

Full list of author information is available at the end of the article

\section{Introduction}

Renal cell carcinoma (RCC) is a malignant tumor that originates from the renal parenchyma urinary tubule epithelia. Clear cell renal cell carcinoma (ccRCC) is the most common pathological type of RCC (60-85\%) [1]. Surgical resection is still the first choice for treatment of localized renal cancer [2]. Because kidney cancer is not sensitive to radiotherapy and chemotherapy, some patients who cannot undergo surgical treatment need to consider targeted

(c) The Author(s) 2020. This article is licensed under a Creative Commons Attribution 4.0 International License, which permits use, sharing, adaptation, distribution and reproduction in any medium or format, as long as you give appropriate credit to the original author(s) and the source, provide a link to the Creative Commons licence, and indicate if changes were made. The images or other third party material in this article are included in the article's Creative Commons licence, unless indicated otherwise in a credit line to the material. If material is not included in the article's Creative Commons licence and your intended use is not permitted by statutory regulation or exceeds the permitted use, you will need to obtain permission directly from the copyright holder. To view a copy of this licence, visit http://creativeco mmons.org/licenses/by/4.0/. The Creative Commons Public Domain Dedication waiver (http://creativecommons.org/publicdomain/ zero/1.0/) applies to the data made available in this article, unless otherwise stated in a credit line to the data. 
therapy. Since the US FDA approved sorafenib treatment of metastatic renal cell carcinoma in 2006, it has successively approved a series of drugs, mainly divided into three categories: 1 Tyrosine kinase inhibitors (TKI) categories: sunitinib, pazopanib, etc.; 2 anti-vascular endothelial growth factors: ranibizumab, bevacizumab, etc.; 3 mammalian target of rapamycin (mTOR) inhibitor: everolimus, temsirolimus, etc. [3]. Although targeted drugs prolong the patient's survival time, their high cost and prolonged use, which leads to the gradual emergence of problems such as drug resistance and toxicity and side effects, limit their widespread use in clinical practice. Therefore, the detailed investigation of the pathogenesis of renal cancer and the search for new targets for targeted therapy of renal cancer are the focus of current research on renal cancer.

Metabolic disorders are one of the important hallmarks of tumors [4]. The proliferation of tumor cells usually requires the re-adjustment of their metabolism to produce enough energy and synthetic raw materials [5]. ccRCC is a tumor characterized by abnormal glucose and lipid metabolism [6]. Numerous studies have shown that multiple pathways associated with gluconeogenesis (e.g., pyruvate metabolism, valeric acid metabolism, arginine and proline metabolism, and degradation of valine, leucine, and isoleucine) are down-regulated in ccRCC [6-8]. ABAT (gamma-aminobutyric acid transaminase) [9] and ALDH6A1 (aldehyde dehydrogenase 6 family, member A1) [10] are involved in the pyruvate metabolism and catabolism of valine, leucine, and isoleucine. Both of them are differential expressed genes (DEGs) of The Cancer Genome Atlas (TCGA)-kidney renal clear cell carcinoma (KIRC) data [11-13]. The role of these two genes in ccRCC development and their gene regulation mechanisms have not been discussed in depth.

Therefore, this study will explore the expression of ABAT and ALDH6A1, their clinical significance and biological functions, correlations between ABAT and ALDH6A1 gene expression, and the transcription factor involved in the regulation of the expression of these two genes in ccRCC.

\section{Methods}

\section{Clinical specimens}

50 cases of renal clear cell carcinoma and matched paracancerous tissues ( $>2 \mathrm{~cm}$ from the edge of the cancer tissue) were selected from fresh resections of kidney cancer patients at Fuzhou General Hospital from November 2013 to November 2015. Patients were aged 28-77 years, with an average age of 55.5 years. All the cancer tissue specimens were pathologically confirmed as ccRCC. The separation and use of human tissues were approved by the Human Research Ethics Review Committee of
Fuzhou General Hospital (Approval No. 2013-017). All patients provided written informed consent. The pathological grades were verified according to the Furhman classification. Additional file 1: Table SI details the patients' details.

\section{Cell lines and main reagents}

HEK293T cells were purchased from the Shanghai Cell Bank of the Chinese Academy of Sciences (Shanghai, China). ACHN and 786-O cells were provided by Shanghai GK Genentech Co., Ltd. (Shanghai, China). Cells freshly amplified and frozen were used every $2-3$ months. They were routinely tested for the absence of mycoplasma contamination. Dulbecco's modified Eagles medium (DMEM) high glucose medium and RPMI 1640 medium were purchased from Hyclone (Thermo Fisher Scientific, Inc.). Fetal bovine serum was purchased from Gibco (Thermo Fisher Scientific, Inc.). Transfection reagent Lipofiter $^{\mathrm{TM}}$ was purchased from HanBio (Shanghai, China). TRIzol was purchased from Invitrogen (Thermo Fisher Scientific, Inc.). A complementary DNA (cDNA) kit was purchased from Fermentas (Thermo Fisher Scientific, Inc.), and a SYBR Green real-time polymerase chain reaction (PCR) kit was purchased from Applied Biosystems (Thermo Fisher Scientific, Inc.). ABAT and ALDH6A1 antibodies were purchased from SigmaAldrich (Merck KGaA, Darmstadt, Germany). ACTIN antibody and Flag-tag antibody were purchased from Cell Signaling Technology (Danvers, MA, USA). A watersoluble tetrazolium salt (WST)-1 cell proliferation assay kit was purchased from Roche (Mannheim, Germany). Horseradish peroxidase (HRP)-tagged secondary antibody and ECL kits were purchased from Pierce (Thermo Fisher Scientific, Inc.).

\section{Gene expression omnibus (GEO) and TCGA data analysis}

We selected four ccRCC data sets on Oncomine (http:// www.oncomine.org): Beroukhim Renal_GSE14994 [14], Grumz Renal_GSE6344 [15], Jones Renal_GSE 15641 [16], and Lenburg Renal_GSE781 [17]. Down-regulated genes were selected from these four datasets. The data of these four primary dataset were downloaded from the NCBI GEO database (http://ncbi.nlm.nig.gov/geo) [18]. KIRC clinical data and mRNA expression were downloaded from the TCGA website (http://cancergeno me.nig.gov) [19]. The transcriptome analysis data file was standardized and then transferred to a txt file using a Perl script. The expression of the ABAT and ALDH6A1 genes is reflected by the intensity of the probe signal. GraphPad Prism 6 software (GraphPad Software, Inc., La Jolla, CA, USA) was used to make gene expression maps. The Kaplan-Meier survival curve of TCGA-KIRC patients was generated on the OncoLnc (http://www.oncol 
nc.org/) website. A Kyoto Encyclopedia of Genes and Genomes (KEGG, http://www.genome.jp/kegg/) pathway analysis of the DEGs was generated by Metascape (http:// metascape.org/gp/index.html\#/main/step1) [20]. Gene set enrichment analysis (GSEA) was analyzed in LinkedOmics (http://www.linkedomics.org/login.php\#) [21]. Gene expression correlation analysis was obtained from UALCAN (http://ualcan.path.uab.edu/index.htmll) [22].

\section{Quantitative polymerase chain reaction}

Total RNA was extracted from tissues using the Total RNA Kit II kit (Omega Bio-Tek, Inc., Norcross, GA, USA). After RNA quantification, $3 \mu \mathrm{g}$ of total RNA was reverse transcribed into cDNA using the RevertAid First Strand cDNA Synthesis kit. SYBR Green select master mix was used for quantitative polymerase chain reaction (qPCR). The cDNA was subjected to $\mathrm{qPCR}$ using ATAT, ALDH6A1, and $\beta$-actin primers: ABAT forward primer, 5'-CTTCCGTCTTCATCAGAGGC-3' and reverse primer, 5'-CAGCTTCCAGCACAGCTACC-3'; ALDH6A1 forward primer, 5'-TGGGACTGGATTTCA CCTTG-3' and reverse primer $5^{\prime}$-GTGCTTCTGGGC AGTAGAGG-3'; and B-actin forward primer $5^{\prime}$-TGA CGTGGACATCCGCAAAG-3' and reverse primer 5'-CTGGAAGGTGGACAGCGAGG-3'. PCR was conducted for 40 cycles under the following conditions: $94{ }^{\circ} \mathrm{C}$ for $30 \mathrm{~s}, 58{ }^{\circ} \mathrm{C}$ for $60 \mathrm{~s}$. Relative fold changes in mRNA expression were calculated by normalization to $\beta$-actin mRNA using the formula $2^{-\Delta \Delta \mathrm{Ct}}$ [23].

\section{Western blotting detection}

SDS-PAGE electrophoresis was performed at $50 \mu \mathrm{g} /$ well for each group of proteins quantified by BCA. After electrophoresis, the cells were transferred to PVDF membranes at a constant pressure of $60 \mathrm{~V}$ for $180 \mathrm{~min}$. The blocking solution was blocked for $1 \mathrm{~h}$ and reacted with the primary antibody at $4{ }^{\circ} \mathrm{C}$ overnight; TBST washed three times; HRP-labeled goat anti-rabbit antibody reaction at room temperature for $1 \mathrm{~h}$, TBST washed four times; added ECL luminescence, exposed on an X-ray film, film development, fixing, washing with water, drying, preservation, and photographing.

\section{Immunohistochemical staining}

A tissue microarray (HKid-CRCC060PG-01; Shanghai Outdo Biotech Co., China) was constructed with formalin-fixed paraffin-embedded 29 paired ccRCC and adjacent non-tumor renal tissues. The demographic information was summarized in Additional file 1: Table S2. The paraffin-embedded sections were stained with antibodies against ABAT or ALDH6A1 antibody (dilution at 1:750 or dilution at 1:3000; HPA041528; HPA029073) at $4{ }^{\circ} \mathrm{C}$ overnight and incubated with secondary antibody. Negative controls were stained with isotype control IgG. Then, the sections were counterstained with hematoxylin and eosin. Immunohistochemical staining intensity was based on the proportion of cell staining and scored from 0 to 3 following criteria described previously [24]. The slides were analyzed by standard light microscopy.

\section{Lentivirus transfection}

The lentivirus pLVX-Puro-ABAT, pLVX-PuroALDH6A1, and control virus pLVX-Puro were purchased from the Public Protein/Plasmid Library (PPL, Nanjing, China). For virus infection, the virus was diluted with serum-containing cell culture medium containing $8 \mu \mathrm{g} / \mathrm{mL}$ polybrene. The fresh medium was changed after $12 \mathrm{~h}$. Puromycin $(1 \mu \mathrm{g} / \mathrm{mL}$, Sigma $)$ was then added to select stable cells (10 days).

\section{Water-soluble tetrazolium detects cell proliferation}

Cells of the observation group, the control group, and the blank group were taken, and the number of cells was adjusted to $2 \times 10^{3}$ cells $/ \mathrm{ml}$, and $100 \mu \mathrm{L}$ cells were inoculated into a 96-well cell culture plate. After $24 \mathrm{~h}$, the cells were adhered and $10 \mu \mathrm{L}$ of water-soluble tetrazolium (WST-1) reagent was added for 24,48 and $72 \mathrm{~h}$ testing, and incubated for $45 \mathrm{~min}$. Then, the optical density (D450) of each well at $450 \mathrm{~nm}$ wavelength was measured with a spectrophotometer (Multiskan GO, Thermo Scientific). Each group set up four complex holes.

\section{Cell death detection}

ABAT, ALDH6A1 stable overexpressed or control ACHN and 786-O cells $\left(1 \times 10^{5} /\right.$ well $)$ were plated and grown in 100 -mm culture dishes overnight. Cells were harvested and cell death rates were determined using a Cell Death Detection ELISA Kit (Cat. No. 11544675001, Roche, Switzerland) following the manufacturer's instructions.

\section{Measurement of lactic acid}

Levels of lactic acid were measured using a Lactate Assay Kit (Sigma-Aldrich, USA) following the manufacturer's instructions. In brief, ABAT, ALDH6A1 stable overexpressed or control ACHN and 786-O cells were treated with Lactate Assay Buffer and the Reaction Mix was added. The reaction mixture was incubated at room temperature for $30 \mathrm{~min}$. The samples were analysed at an absorbance at $450 \mathrm{~nm}$ using a spectrophotometer.

\section{Measurement of NADPH and NADP}

Levels of NADPH and NADP + were measured using a NADP/NADPH Quantitation Kit (Sigma-Aldrich, USA) following the manufacturer's instructions. In brief, ABAT, ALDH6A1 stable overexpressed or control ACHN and 
786-O cells were treated with NADP/NADPH extraction buffer and the NADPH developer was added. The reaction mixture was incubated at room temperature for $1 \mathrm{~h}$. The samples were analysed at an absorbance at $450 \mathrm{~nm}$ using a spectrophotometer (Multiskan GO, Thermo Scientific).

\section{Plasmid and transfection}

The pHNF4A-flag and its control plasmid were purchased from the Public Protein/Plasmid Library (PPL, Nanjing, China). HEK293T and ACHN cells were transfected with pHNF4A-flag or control plasmid. At $48 \mathrm{~h}$ after transfection, the cells were extracted for quantitative PCR and Western blot assay.

\section{Luciferase assay}

HEK293 cells were plated in 24-well plates and were co-transfected with $100 \mathrm{ng}$ of reporter construct (pGL3-Basic, pGL3-ABAT-promoter, or pGL3ALDH6A1-promoter), $500 \mathrm{ng}$ of HNF4A expression vector or control vector, and $20 \mathrm{ng}$ of the internal Renilla vector using Lipofiter. After $48 \mathrm{~h}$, the luciferase activity was measured using a dual luciferase reporter assay system (Promega, Madison, WI, USA).

\section{Chromatin immunoprecipitation assay}

HEK293T cells were transfected with pcDNA3.1HNF4A-flag plasmid using Lipofiter. The chromatin immunoprecipitation (ChIP) assay was performed using a SimpleChIP Plus Enzymatic Chromatin IP Kit (Magnetic Beads) (cell signaling technology) following the manufacturer's protocol. Cross-linked chromatin was immunoprecipitated with anti-flag rabbit polyclonal antibody (\#14793; Cell Signaling Technology) or normal rabbit IgG (Cell Signaling Technology) antibodies. Precipitated DNA was analyzed by quantitative real-time PCR and semi-quantitative PCR. The primers specific to the HNF4A binding region within ABAT promoter region were as follows: forward-1 5'-GTTCATAGGGAT TGGATTGCT- $3^{\prime}$ and reverse- 1 5'-CCCCTTTACTAC CCTTGACCT-3'; and forward-2 $5^{\prime}$ - ATCAACCTATGG AGCTGCCCC $-3^{\prime}$ and reverse- $25^{\prime}$ - CTCGCTTTCGCC ACAGCCAAT $-3^{\prime}$. The primers within ALDH6A1 promoter region were as follows: forward-1 5'-ATCTAG CGCAAAAGGGGCAA- $3^{\prime}$ and reverse-1 $5^{\prime}$-GCTTTG GGAGACCAAAAGATGAC-3'; and forward-2 5'-ACA TCTCCTCCTCGACCCTC- $3^{\prime}$ and reverse-2 $5^{\prime}$-TCA GCTCACCGGTTCTTCAC-3'

\section{Statistical processing}

SPSS13.0 software was used for statistical analysis. The data obtained were expressed in terms of mean \pm SD.
Single-factor repeated-measures analysis of variance found a statistically significant difference at $p<0.05$.

\section{Results}

Identification of ABAT and ALDH6A1 as downregulated genes in ccRCC by GEO data analysis

Data mining was performed on the Oncomine database, and four data sets were selected, all of which were detected using the Affymetrix genomic array (Human Genome U133A Array). ABAT and ALDH6A1 were determined to be the downregulated DEGs (Fig. 1a). KEGG pathway enrichment (Metascape) revealed that the top 120 down-regulated DEGs were correlated with the biosynthesis of amino acids, carbon metabolism, endocrine and other factor-regulated calcium reabsorption, valine, leucine and isoleucine degradation, and lysine degradation pathways (Fig. 1b).

The expression of ABAT and ALDH6A1 was significantly reduced in human ccRCC samples among all four datasets (Fig. 2a, b) (Beroukhim Renal non-hereditary and hereditary ccRCC, $\mathrm{n}=59$, fold change $=-11.183, p<0.001$ (ABAT), fold change $=-9.122, p<0.001$ (ALDH6A1); Grumz Renal ccRCC, $n=10$, fold change $=-10.795, p<0.001$ (ABAT), fold change $=-5.828, p<0.001$ (ALDH6A1); Jones Renal ccRCC, $n=32$, fold change $=-3.972, p<0.001$ (ABAT), fold change $=-4.413, p<0.001$ (ALDH6A1); and Lenburg Renal ccRCC, $n=12$, fold change $=-11.243$, $p<0.001) \quad(\mathrm{ABAT}), \quad$ fold change $=-8.680, \quad p<0.001$ (ALDH6A1)). Protein association network analysis was performed by STRING. The result shows that ABAT and ALDH6A1 were both involved in the valine, leucine, and isoleucine degradation and beta-alanine metabolism pathways (Fig. 2c).

\section{ABAT and ALDH6A1 are downregulated in TCGA renal clear cell carcinoma data}

In the TCGA-KIRC dataset, there were 72 paraneoplastic tissues and 538 tumor tissues. The results still showed decreased expression of ABAT and ALDH6A1 in tumor compared with paraneoplastic tissues $(p<0.0001)$ (Fig. 3a, b). The expression of ABAT and ALDH6A1 was decreased in the four pathologically graded tissues, but there was no significant difference between the individual grades, see Fig. 3c, d. Analysis of patient survival revealed that patients with relatively low expression of ABAT or ALDH6A1 tended to have shorter overall survival (Fig. 3e-f). These results suggest that the down-expression of ABAT and ALDH6A1 could be used as biomarkers for ccRCC and that their expression correlates with the survival of patients.

Based on the pan-cancer analysis, both ABAT and ALDH6A1 were significantly down-expressed in three 
$\mathbf{a}$

\begin{tabular}{|c|c|c|c|}
\hline Median Rank & p-Value & Gene & \\
\hline 32.5 & $1.23 \mathrm{E}-15$ & SFRP1 & \\
\hline 38.5 & $5.95 \mathrm{E}-7$ & TMPRSS2 & \\
\hline 57.0 & $8.72 \mathrm{E}-7$ & CALB1 & \\
\hline 62.0 & $1.22 \mathrm{E}-9$ & KCNJ1 & \\
\hline 64.5 & $2.72 \mathrm{E}-6$ & ALDOB & \\
\hline 72.0 & $4.01 \mathrm{E}-6$ & ALDH6Al & \\
\hline 74.0 & $3.68 \mathrm{E}-6$ & ATP6V0A4 & \\
\hline 77.5 & $4.86 \mathrm{E}-6$ & GATA3 & \\
\hline 86.0 & $1.54 \mathrm{E}-10$ & $\mathrm{~S} 100 \mathrm{~A} 2$ & \\
\hline 87.0 & $1.34 \mathrm{E}-6$ & KNC1 & \\
\hline 87.5 & $2.76 \mathrm{E}-9$ & ERBB 4 & \\
\hline 94.5 & $7.87 E-10$ & ProSAPiPI & \\
\hline 101.0 & $2.77 \mathrm{E}-8$ & PAH & \\
\hline 102.0 & $2.60 \mathrm{E}-10$ & SERPINAS & \\
\hline 102.5 & $4.71 \mathrm{E}-6$ & ALAD & \\
\hline 102.5 & $6.28 \mathrm{E}-6$ & LPPR1 & \\
\hline 104.5 & 4.56E-9 & TFCP2L1 & \\
\hline 111.5 & $2.30 \mathrm{E}-6$ & ACSF2 & \\
\hline 113.0 & $7.06 \mathrm{E}-20$ & UMOD & \\
\hline 118.5 & $3.46 \mathrm{E}-6$ & ARC2 & \\
\hline & & & \begin{tabular}{|l|l|l|}
1 & 2 & 3 \\
\end{tabular} \\
\hline
\end{tabular}

\begin{tabular}{|c|c|c|}
\hline Median Rank & p-Value & Gene \\
\hline 118.5 & $6.47 \mathrm{E}-6$ & MAN $1 C 1$ \\
\hline 120.5 & $1.17 E-8$ & PTPRO \\
\hline 121.5 & $3.56 \mathrm{E}-6$ & DEFBI \\
\hline 123.5 & $5.25 \mathrm{E}-6$ & ABAT \\
\hline 138.0 & $1.40 \mathrm{E}-9$ & GABARAPL3 \\
\hline 141.5 & $9.17 \mathrm{E}-6$ & CLDN8 \\
\hline 143.5 & $2.84 \mathrm{E}-8$ & PAPPA \\
\hline 145.5 & $4.76 \mathrm{E}-7$ & PTHIR \\
\hline 151.5 & $4.11 E-8$ & GABARAPLI \\
\hline 158.5 & $5.13 E-9$ & $\mathrm{HAO} 2$ \\
\hline 159.5 & $3.39 \mathrm{E}-9$ & NPHS2 \\
\hline 162.5 & $1.07 E-8$ & ASS1 \\
\hline 163.5 & $4.11 \mathrm{E}-10$ & AP1M2 \\
\hline 164.0 & $1.08 \mathrm{E}-5$ & OGDHL \\
\hline 167.5 & $1.47 \mathrm{E}-5$ & AMFR \\
\hline 177.5 & $1.61 \mathrm{E}-5$ & SELENBP1 \\
\hline 179.0 & $1.64 \mathrm{E}-5$ & HRG \\
\hline 180.5 & $1.41 E-5$ & CPDIL \\
\hline 182.0 & $4.57 \mathrm{E}-8$ & CLYAT \\
\hline 189.0 & $5.53 \mathrm{E}-6$ & $\cos 2$ \\
\hline & & \\
\hline
\end{tabular}

1. Beroukhim Renal, Cancer Res, 2009

3. Jones Renal, Clin Cancer Res, 2005
2. Gumz Renal, Clin Cancer Res, 2007

4. Lenburg Renal, BMC Cancer, 2003

\section{$1 \quad 5 \quad 25 \quad 2510 \quad 5 \quad 1$
$\square \square \square \square \square \square \square \square$ Not measured}

b

KEGG pathway (Metascape)

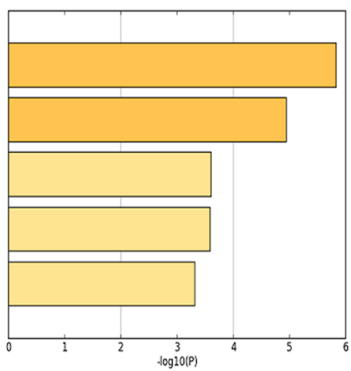

hsa01230: Biosynthesis of amino acids

hsa01200: Carbon metabolism

hsa04961: Endocrine and other factor-regulated calcium reabsorption

hsa00280: Valine, leucine and isoleucine degradation

hsa00310: Lysine degadation

Fig. 1 ABAT and ALDH6A1 expressions are downregulated in $C C R C C$ based on Oncomine data mining. a Differential expression analysis was performed using Oncomine online analysis tools. b KEGG pathway analysis of low expressed DEGs in Metascape. Statistical significance was set at the $p<0.05$ level. KEGG: Kyoto Encyclopedia of Genes and Genomes

types of renal cell carcinomas, KIRC, kidney renal papillary cell carcinoma (KIRP), and kidney chromophobe (KICH) (Fig. 3g-h). ABAT and ALDH6A1 have similar expression profiles in cancers.

\section{Expression of ABAT and ALDH6A1 is downregulated} in cCRCC clinical samples

From 2013 to 2015, our center collected a total of 50 pairs of pathologically identified and surgically 


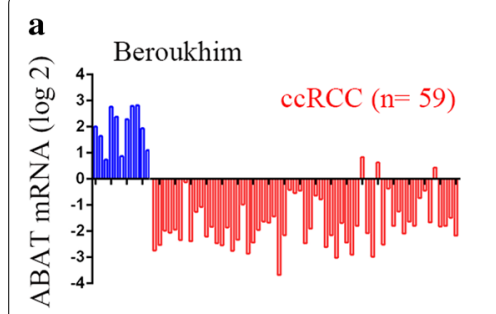

Kidney $(n=11)$

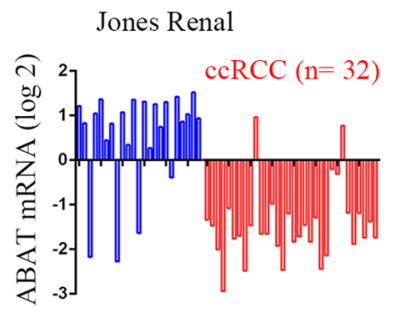

Kidney $(n=23)$

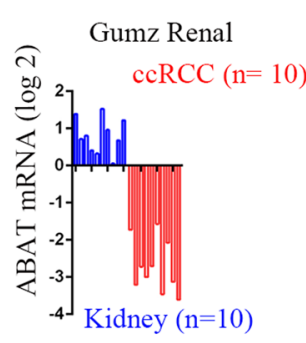

Lenburg

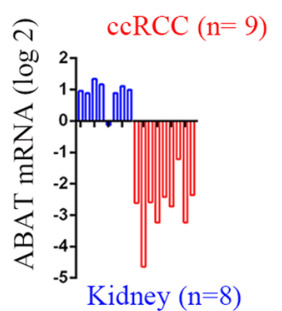



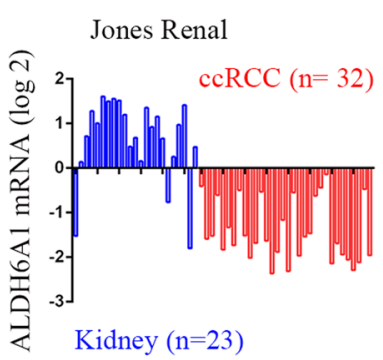

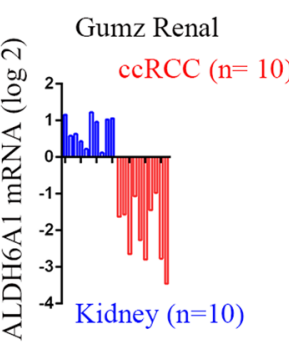

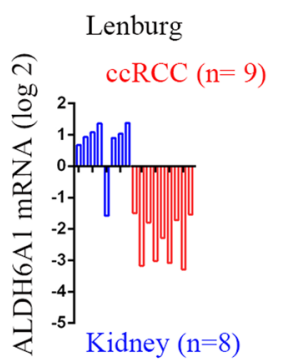

c

\begin{tabular}{|llll|}
\hline \multicolumn{4}{c|}{ KEGG Pathways } \\
\hline pathway & description & false discovery rate \\
\hline hsa00280 & Valine, leucine and isoleucine degradation & $1.75 \mathrm{e}-14$ & (9) \\
\hline hsa01100 & Metabolic pathways & $5.88 \mathrm{e}-14$ & 0 \\
\hline hsa00410 & beta-Alanine metabolism & $2.18 \mathrm{e}-13$ & 0 \\
\hline hsa00650 & Butanoate metabolism & $4.67 \mathrm{e}-11$ & 0 \\
\hline hsa00640 & Propanoate metabolism & $6.85 \mathrm{e}-11$ & 0 \\
\hline
\end{tabular}

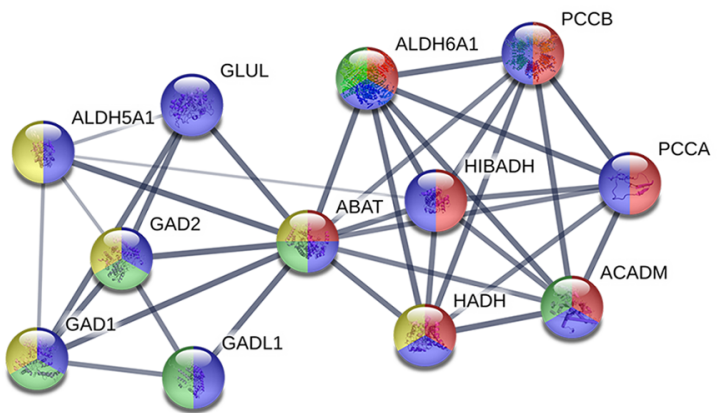

Fig. 2 ABAT and ALDH6A1 expression reduced in data analysis of four GEO datasets and assay of their interaction networks. a Bar charts of the ABAT mRNA levels $(\log 2)$ in the four GEO datasets. Blue represents non-tumor tissues and red represents ccRCC tissues. ccRCC, clear cell renal cell carcinoma. b Bar charts of the ALDH6A1 mRNA levels (log2) in the four GEO datasets. c ABAT and ALDH6A1 interaction genes predicted by STRING analysis

removed ccRCC tumor tissues and their adjacent tissues. Fluorescent quantitative PCR assays showed that ABAT expression was reduced in $94 \%$ of tumor tissues (Fig. 4a). The paired analysis showed that ABAT mRNA levels were significantly decreased in renal clear cell carcinoma tissue $(p<0.0001)$ (Fig. 4b). Similar results were observed in ALDH6A1 expression (Fig. 4c, d).

A ccRCC paraffin tissue microarray was used for immunohistochemical detection. Results showed that ABAT protein levels were reduced in ccRCC tissues (Fig. 4e), which reduction was statistically significant $(p<0.0001)$ (Fig. 4f). Similar results were observed for ALDH6A1 protein levels (Fig. 4g-h). These data indicate significant decreases in ABAT and ALDH6A1 expression in the ccRCC clinical samples.

\section{Overexpression ABAT or ALDH6A1 suppresses renal clear} cell carcinoma cell line growth and migration

We next sought to examine the functions of ABAT and ALDH6A1 in ccRCC cells using a lentivirus-mediated overexpression system. The high expression of ABAT and ALDH6A1 was confirmed in ACHN cells (Fig. 5a). The results of WST-1 assay showed that the proliferation of ABAT and ALDH6A1 overexpression group was significantly lower than that in the control group at $72 \mathrm{~h}$ ( $p<0.05$, Fig. 5b). Compared with the control group, the ACHN cells with stable ABAT or ALDH6A1 expression had a significantly reduced ability to form colonies (Fig. 5c). We further assessed the effects of ABAT and ALDH6A1 on cell death. Using cell death ELISA assay, it was observed that overexpression of ABAT and ALDH6A1 increased death rates in ACHN cells (Fig. 5d). 

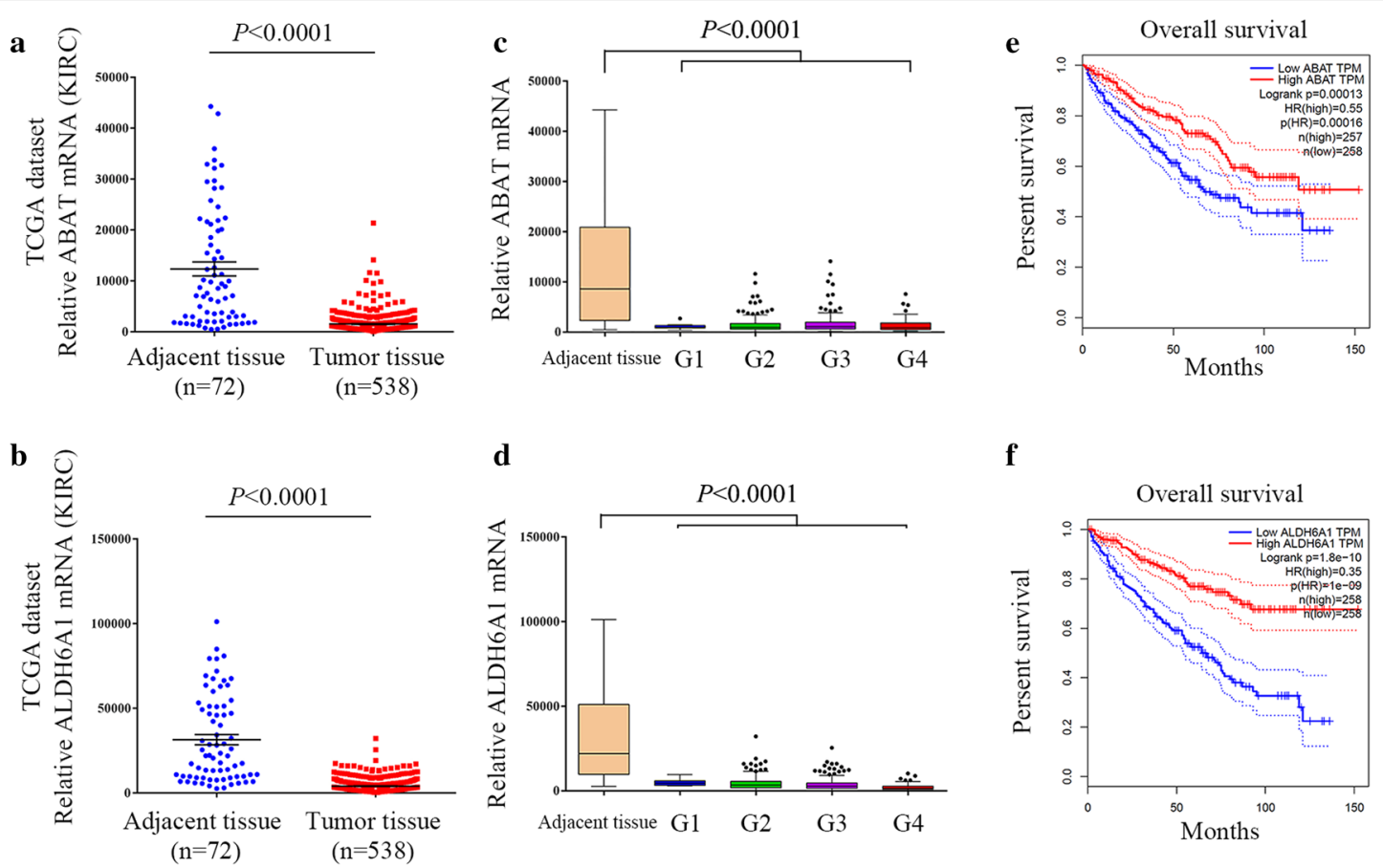

Expression of ABAT across TCGA cancers (with tumor and normal samples)

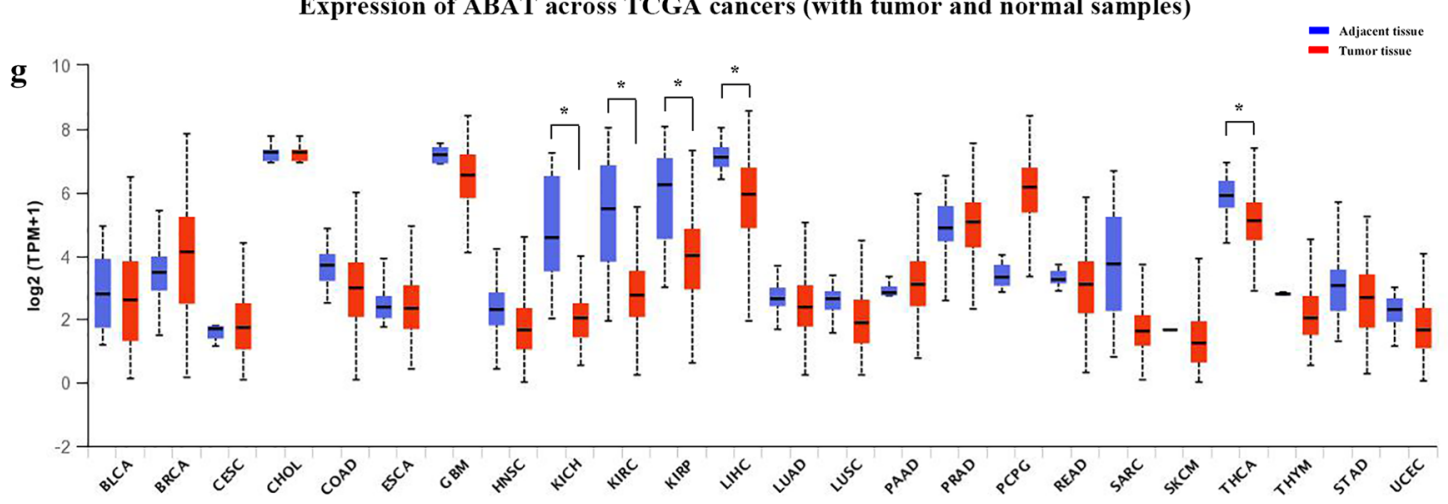

Expression of ALDH6A1 across TCGA cancers (with tumor and normal samples)

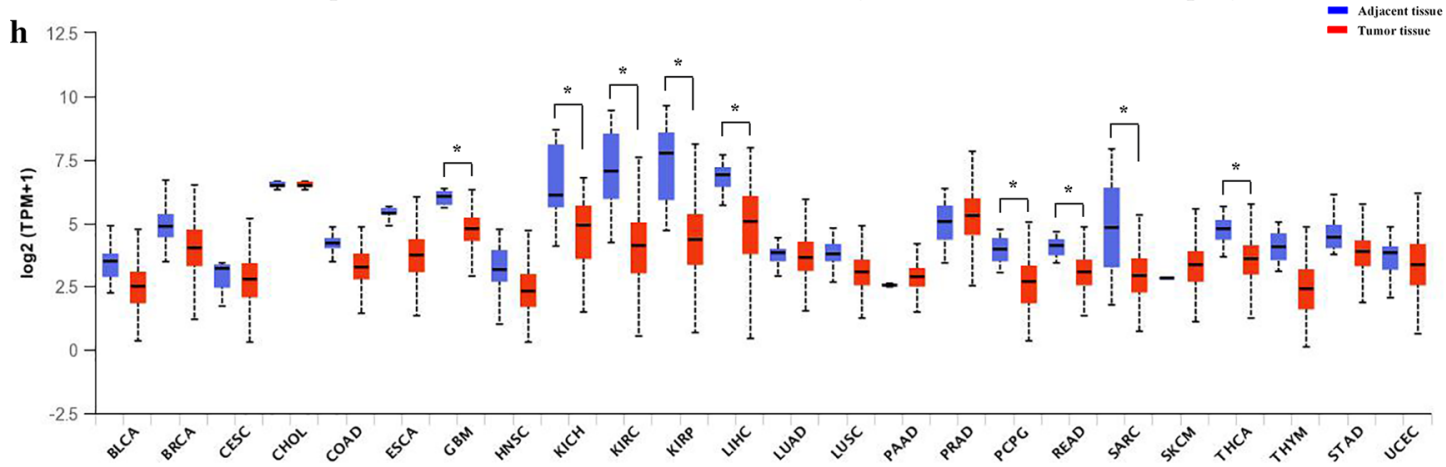

Fig. 3 Analysis of renal clear cell carcinoma data in TCGA. a Relative expression of ABAT in ccRCC tissues and non-tumor tissues; $p<0.0001$. b Box plots of ABAT mRNA levels in neoplastic tissues, Fuhrman grades Gl, G2, G3, and G4. c Survival curves of patients with relatively low and high expression of ABAT in cCRCC patients. d Relative expression of ALDH6A1 in ccRCC tissues and non-tumor tissues; $p<0.0001$. e Box plots of ALDH6A1 mRNA levels in neoplastic tissues. $\mathbf{f}$ Survival curves of ccRCC patients with relatively low and high expression of ALDH6A1. g ABAT gene expression profile across all TCGA tumor samples and paired normal tissues. $\mathbf{h}$ ALDH6A1 gene expression profile across all TCGA tumor samples and their normal tissues. KIRC, Kidney renal clear cell carcinoma 




a
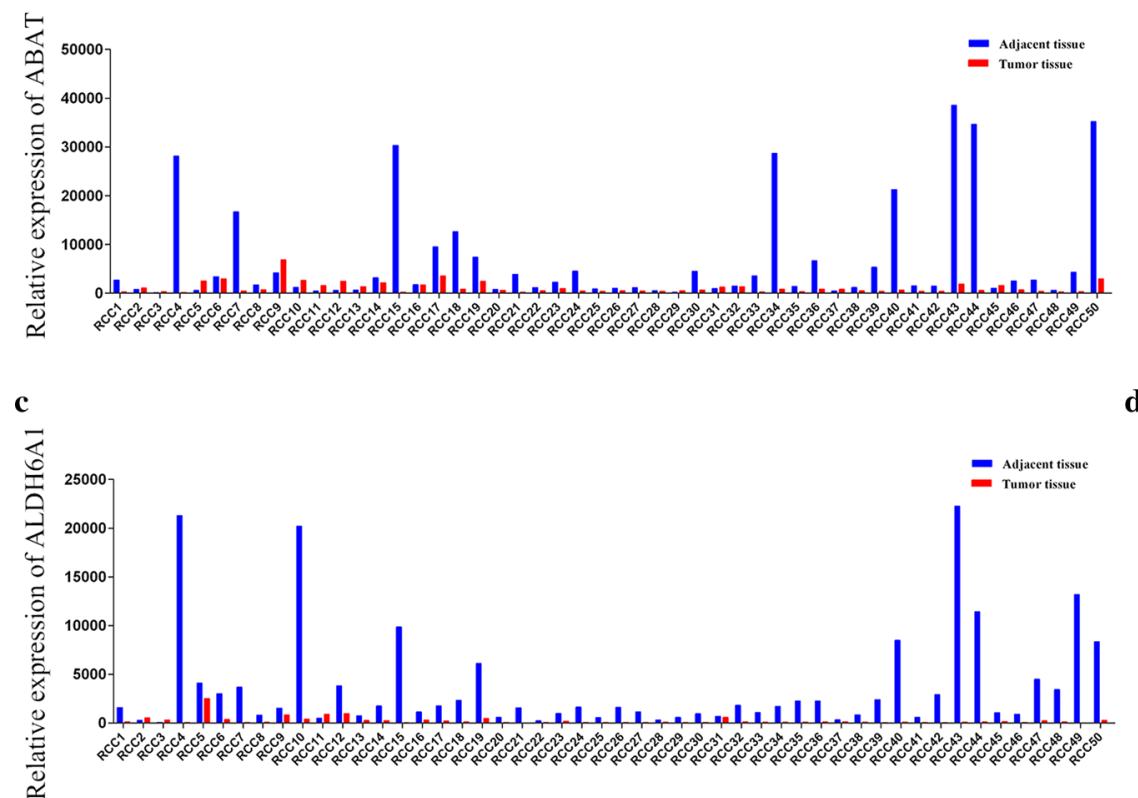

b



d

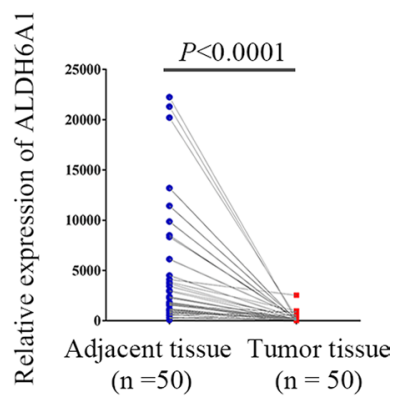

e

Paired of ccRCC tissues

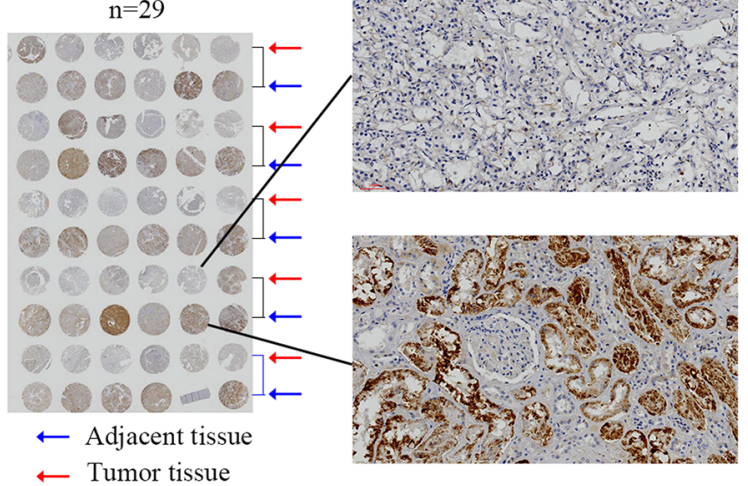

g Paired of ccRCC tissues $\mathrm{n}=29$

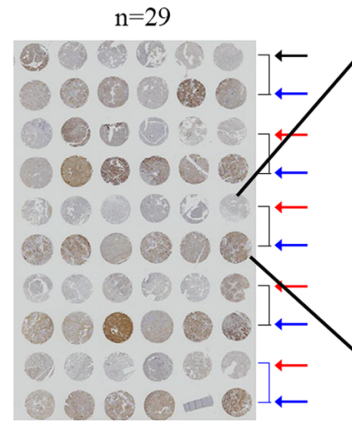

$\leftarrow$ Adjacent tissue

$\leftarrow$ Tumor tissue

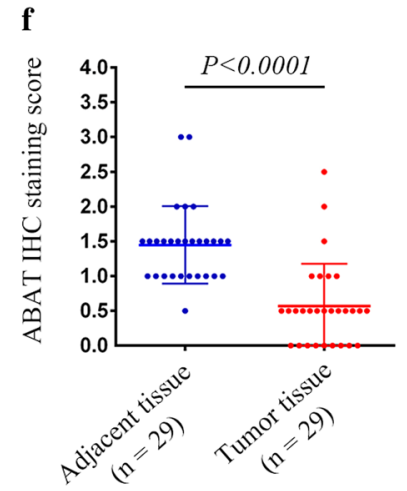

h

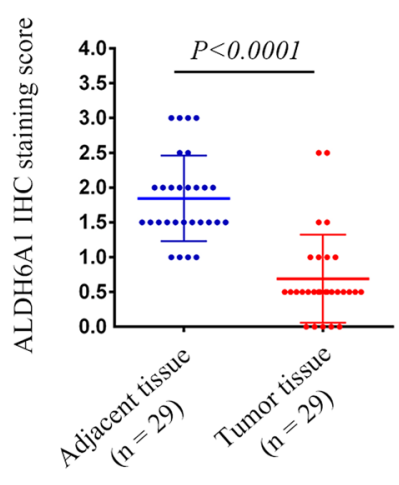

Fig. 4 ABAT and ALDH6A1 expression in cCRCC clinical samples. a 50 pairs of $c C R C C$ organizations were used to detect ABAT mRNA levels by quantitative-PCR. $\mathbf{b}$ Paired analysis of ABAT mRNA detection; $p<0.0001$. $\mathbf{c}$ For 50 pairs of $c$ RCC samples, quantitative PCR was used to detect ALDH6A1 mRNA levels. d Paired analysis of ALDH6A1 mRNA detection; $p<0.0001$. e Immunohistochemical detection of ABAT. f Box plot depicting ABAT levels as assessed by IHC in 29 paired ccRCC samples; $p<0.0001 . \mathbf{g}$ Immunohistochemical detection of ALDH6A1. $\mathbf{h}$ Box plot depicting ALDH6A1 levels as assessed by IHC in 29 paired ccRCC samples; $p<0.0001$ 

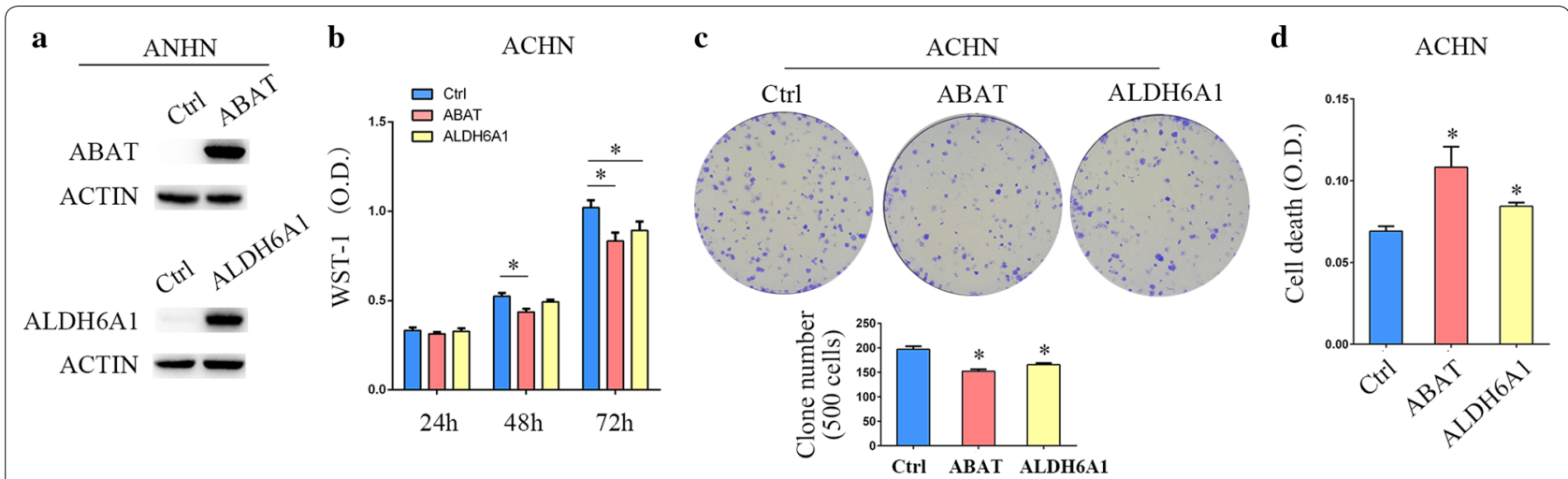

e

f

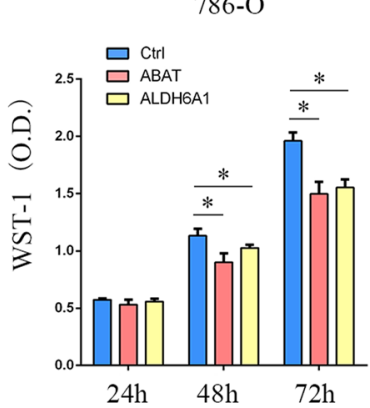

g

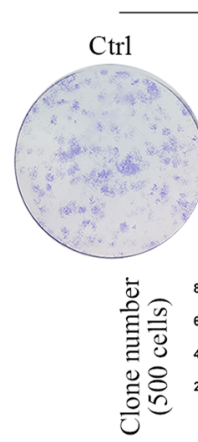

786-O

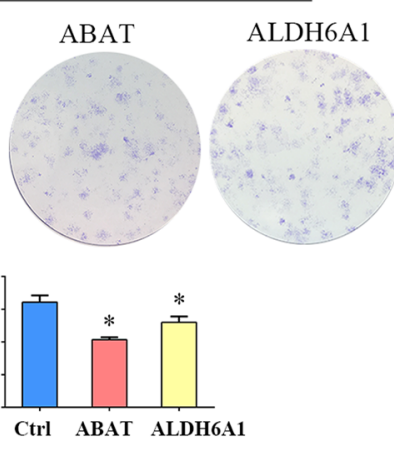

h

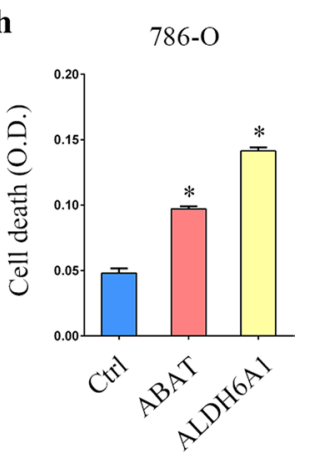

i<smiles></smiles>

Ctrl



$786-\mathrm{O}$

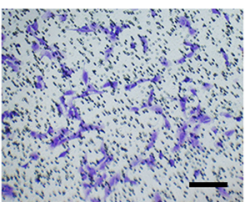

ABAT

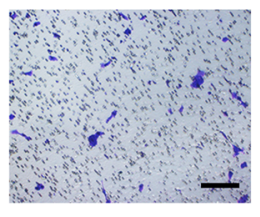

ALDH6Al

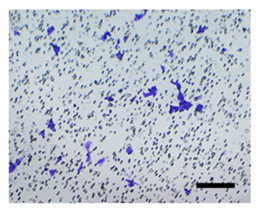

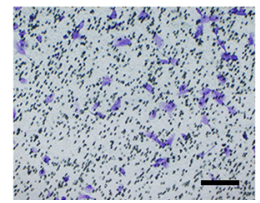

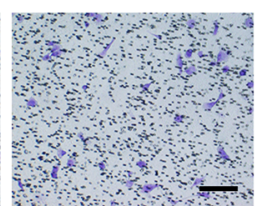

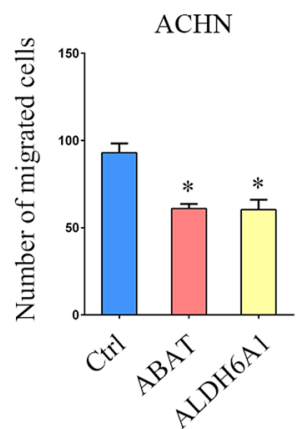

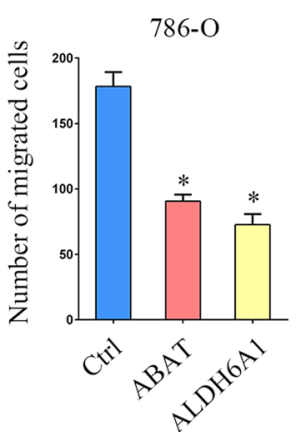

Fig. 5 Effects of overexpression of ABAT and ALDH6A1 on cCRCC cell growth. a ACHN cells stably transfected with ABAT or ALDH6A1 lentivirus and performed by Western blot analysis. $\mathbf{b}$ The growth inhibition rates were measured by WST-1 assay kit at 24, 48, and $72 \mathrm{~h}$ in ACHN cells that stably expressed ABAT or ALDH6A1. c Representative images of clonogenic assays of ACHN cells that stably expressed ABAT or ALDH6A1. d ACHN cells stably expressed ABAT or ALDH6A1. Cell death was detected using an ELISA-based cell death detection kit. e Western blot assay was performed in ABAT or ALDH6A1 overexpressed 786-O cells. $\mathbf{f W S T} 1$ assay in 786-O cells that stably expressed ABAT or ALDH6A1. $\mathbf{g}$ Colony formation assay in 786-O cells that stably expressed ABAT or ALDH6A1. $\mathbf{h}$ Cell death assay in 786-O cells that stably expressed ABAT or ALDH6A1. i Representative images of migration assays of ACHN cells stably expressing ABAT or ALDH6A1 (left) and quantification of the relative migration cell number (right). Scale bar, $100 \mu \mathrm{m}$. All experiments were repeated three times. The $p$ value was measured using Student's $t$-test; ${ }^{*} p<0.05$, compared with the control cells. Ctrl: cells transfected with empty control lentivirus

Those data were verified in the 786-O cell line, another ccRCC cell line (Fig. 5e-h). Moreover, cell migration was significantly decreased in the ABAT or ALDH6A1 overexpression ACHN and 786-O cells (Fig. 5i). These data 
collectively indicate that ABAT and ALDH6A1 act as tumor suppressors of ccRCC.

\section{ABAT and ALDH6A1 overexpression impairs metabolic modeling in cCRCC cells}

To investigate the effects of metabolic enzymes ABAT and ALDH6A1 on ccRCC metabolism and the role of gene abnormalities in driving ccRCC tumorigenesis, TCGA data were used to analyze gene set enrichment analysis (GSEA) of ABAT and ALDH6A1. Besides the valine, leucine, and isoleucine degradation pathway, the citrate cycle (TCA cycle) and fatty acid degradation correlated with downregulated levels of ABAT and ALDH6A1 (Fig. 6a, b). These metabolism pathways are known to be dysregulated in cancers, especially in ccRCC. Cell-proliferation-related pathways were found to be negatively correlated with ABAT and ALDH6A1, such as the cell cycle pathway with ABAT (Fig. 6c) and DNA replication pathway with ALDH6A1 (Fig. 6d). Increased production of lactic acid and NADPH are prominent characteristics of the metabolic remodeling of tumor cells [25]. To further confirm the link between ABAT and ALDH61 expression and metabolic modeling in ccRCC, we measured lactate levels and the NADPH/ $\mathrm{NADP}+$ rate in ACHN and 786-O cells. We found that upregulated ABAT or ALDH6A1 impaired lactate production (Fig. 6e), and ABAT overexpression decreased the ratio of NADPH/NADP + (Fig. 6f). These data suggest that overexpression of ABAT or ALDH6A1 impairs cell oncologic-metabolism.

\section{Transcription factor HNF4A regulates ABAT and ALDH6A1 gene expression}

In UALCAN, ALDH6A1 is the most expression-related gene of ABAT through Pearson correlation analysis, with a Pearson correlation coefficient (Pearson-CC) $=0.66$ (Fig. 7a). By analyzing the transcription factors binding to the ABAT and ALDH6A1 promoters, we found that transcription factor HNF4A could simultaneously regulate ABAT and ALDH6A1, and HNF4A has a positive correlation with ABAT and ALDH6A1 expression (Fig. 7b). HNF4A is a well-known suppressor of ccRCC [26]. The expression of HNF4A is significantly downregulated in ccRCC and loss of HNF4A promotes tumorigenesis in the kidney [27]. We analyzed the promoter sequence of $2000 \mathrm{bp}$ before the transcription initiation site on Jaspar. Four common binding sequences of HNF4A were selected (Fig. 7c). In each of the promoter regions of ABAT and ALDH6A1, there are two regions with more transcription factor binding sites (Fig. 7d).

To examined whether ABAT and ALDH6A1 expressions in renal cell lines are regulated by exogenous HNF4A, HEK293T and ACHN cells were transfected with HNF4A expression vector or control plasmid. 786-O cells were not used in the transfection experiments because of the inability to achieve high transfection efficiency in 786-O cells. As shown in the Fig. 8a, exogenous overexpression of HNF4A induced the mRNA levels of endogenous ABAT and ALDH6A1 in HEK293T and ACHN cells. ABAT and ALDH6A1 protein levels were also significantly increased in HNF4A overexpressing cells (Fig. 8b). To further verify that HNF4A directly targets the promoter of ABAT and ALDH6A1, we performed a ChIP assay to assess the HNF4A-DNA interaction. Figure $8 \mathrm{c}$ demonstrates that Flag antibody co-immunoprecipitated the DNA sequence from the ABAT and ALDH6A1 promoter region by ordinary PCR. Real-time quantitative PCR showed similar results. Luciferase-based assays were subsequently used to verify the regulated role of HNF4A. As expected, in co-transfection experiments with pGL3-ABAT-promoter or pGL3ALDH6A1-promoter and pHNF4A-Flag in HEK293T cells, we found that HNF4A increased the promoter activities of ABAT and ALDH6A1 (Fig. 8d). Together, these data indicate that HNF4A directly regulate expression of ABAT and ALDH6A1.

\section{Discussion}

In this study, we first analyzed four of the GEO datasets and TCGA-KIRC data and found that the expression of ABAT and ALDH6A1 was decreased in ccRCC. The patients with low ABAT or ALDH6A1 gene expression had a worse survival period. Two ccRCC cell lines, ACHN and 786-O, were infected with ABAT or ALDH6A1 overexpressing lentivirus. The ability of cell clone formation was decreased in ABAT or ALDH6A1 overexpression cells, and the percentage of cell death was higher than in the control group. Transwell chamber experiments found that the cell migration ability of ABAT or ALDH6A1-overexpressed cells was inhibited. In order to understand the mechanism of overexpressing ABAT or ALDH6A1 in renal cancer cells, database analysis shows that ABAT and ALDH6A1 are mainly involved in oncologic metabolism. By measuring the lactic acid production and NADP/NADPH ratio of renal cancer cells, the results showed that after ABAT or ALDH6A1 overexpression, oncologic metabolism was impaired. We also demonstrated that ABAT and ALDH6A1 are directly regulated by a well-known tumor suppressor, transcription factor HNF4A.

In the present study, low ABAT expression is significantly associated with basal-like breast cancer aggressiveness by activating gamma-aminobutyric acid (GABA) signaling. Patients with ABAT deficiency display poor chemotherapy treatment outcome [28]. ABAT and ALDH6A1 are proved to be hub genes in association 


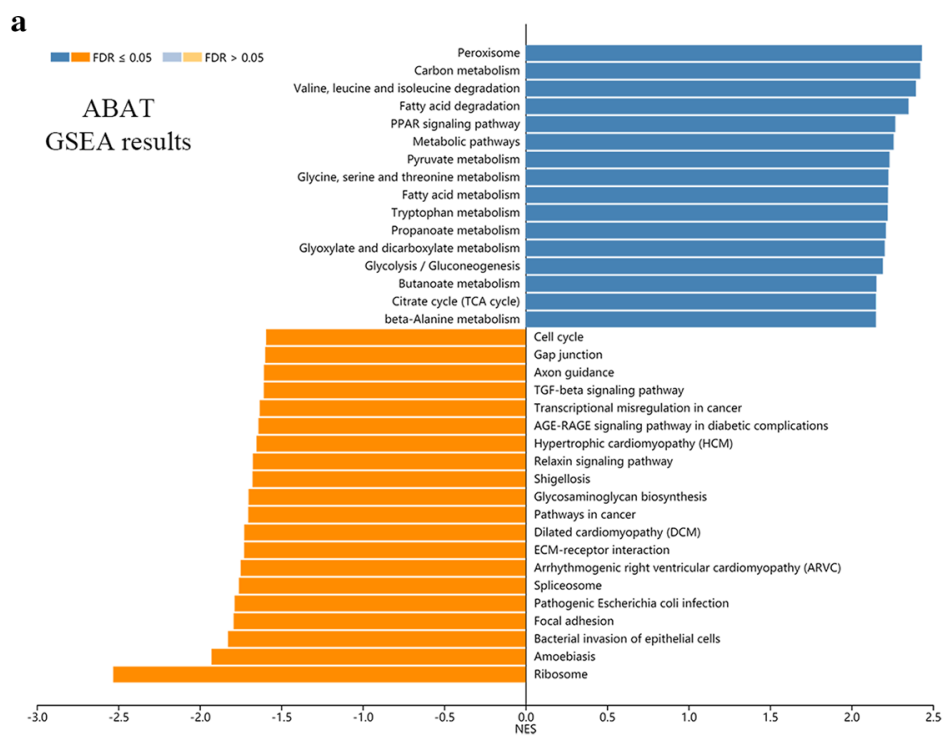

c

VALINE_LEUCINE_AND_ISOLEUCINE_ DEGRADATION

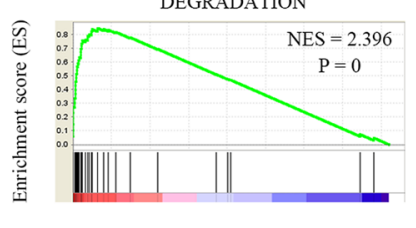

CITRATE_CYCLE_TCA_CYCLE
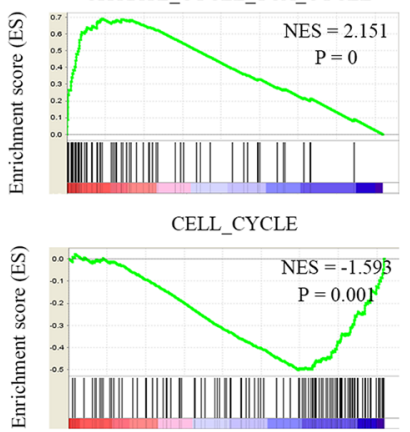

b

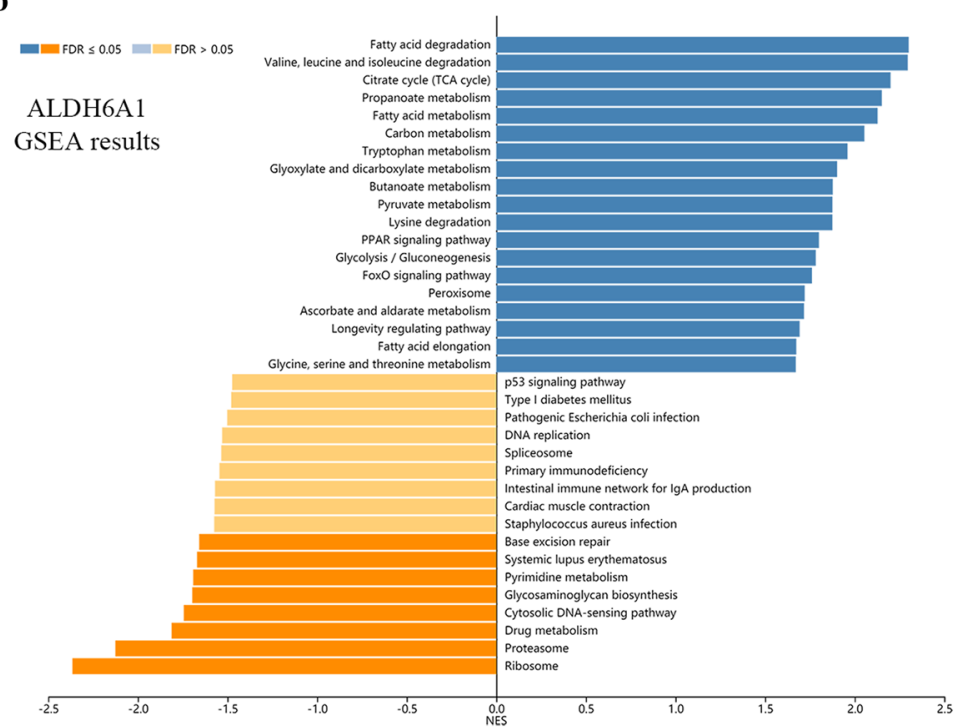

d VALINE_LEUCINE_AND_ISOLEUCINE

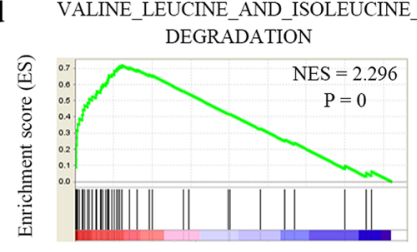

FATTY_ACID_METABOLISM



DNA REPLICATION

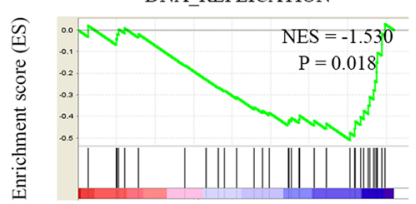

e

786-O

$\square_{\text {ABAT }}^{\text {Ctrl }}$

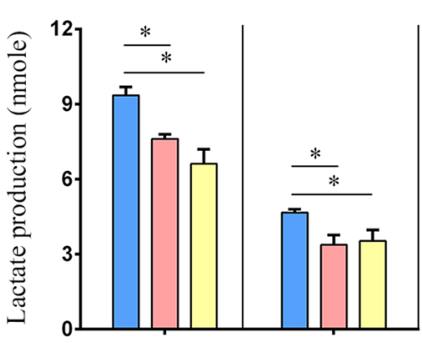

f

$\mathrm{ACHN} \quad 786-\mathrm{O}$

ALDHA

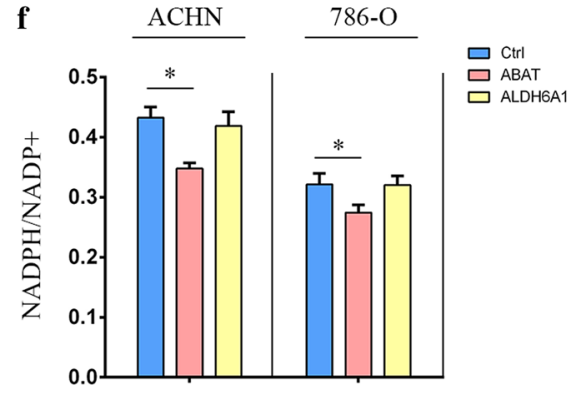

Fig. 6 Effects of overexpression of ABAT and ALDH6A1 on cCRCC cell oncologic-metabolism. a LinkedOmics GSEA KEGG analysis of ABAT co-expression genes in TCGA-KIRC samples. b LinkedOmics GSEA KEGG analysis of ALDH6A1 co-expression genes in TCGA-KIRC samples. c Three KEGG pathways of ABAT. $\mathbf{d}$ Three KEGG pathways of ALDH6A1. e The lactate levels were measured. $\mathbf{f}$ The NADPH/NADP + ratios were measured. All the experiments were repeated three times; $p$-values were calculated compared with that of the control cells (Ctrl), and measured with Student's t-tests; ${ }^{*} p<0.05$ 


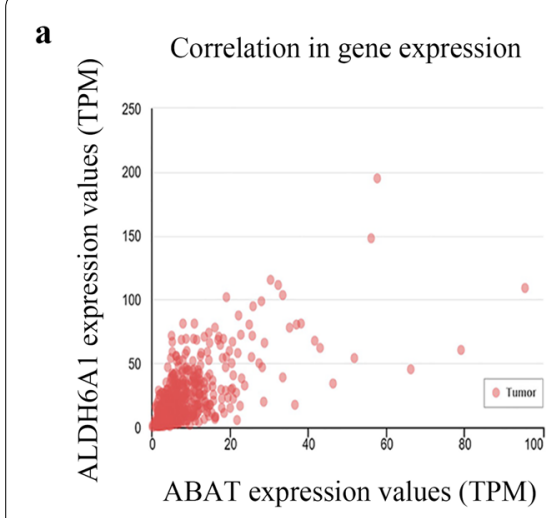

b
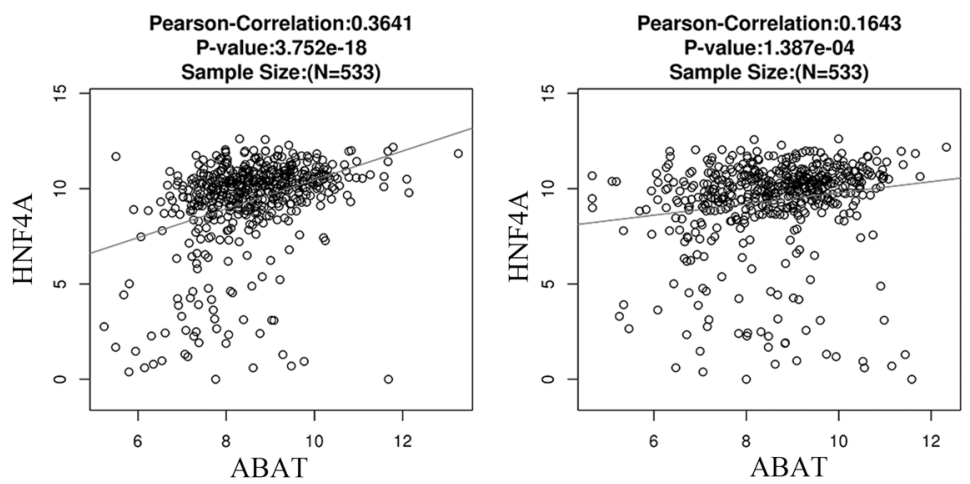

c

MA0114.1

MA0114.2

PB0030.1

PB0134.1

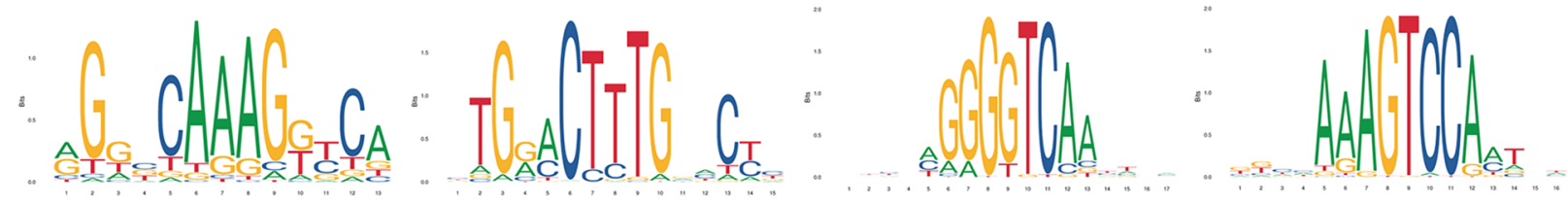

d

\begin{tabular}{|l|l|l|l|l|r|r|r|l||}
\hline Matrix ID & \multicolumn{1}{|c|}{ Name } & \multicolumn{1}{|c|}{ Score } & \multicolumn{1}{|c|}{ Relative score } & \multicolumn{1}{c|}{ Sequence ID } & \multicolumn{1}{c|}{ Start } & \multicolumn{1}{c|}{ End } & Strand & \multicolumn{1}{c|}{ Predicted sequence } \\
\hline MA0114.1 & HNF4A & 8.64526 & 0.82014196 & ABAT & 170 & 182 & + & AGATCAAAGGGTC \\
\hline MA0114.2 & HNF4A & 5.3523 & 0.80611506 & ABAT & 169 & 183 & - & TGACCCTTGATCTA \\
\hline PB0030.1 & HNF4A & 14.2463 & 0.93112505 & ABAT & 172 & 188 & + & ATCAAAGGGTCAACTTA \\
\hline MA0114.1 & HNF4A & 8.00487 & 0.80474957 & ABAT & 239 & 251 & - & AGTAGAAAGATCA \\
\hline MA0114.2 & HNF4A & 5.33423 & 0.80587453 & ABAT & 238 & 252 & + & GTGATCTTCTACTG \\
\hline MA0114.1 & HNF4A & 8.39846 & 0.81420991 & ABAT & 422 & 434 & + & AGGTCAAGGGTAG \\
\hline MA0114.1 & HNF4A & 8.04193 & 0.8056405 & ABAT & 1740 & 1752 & + & GGGTCAGGGTCCC \\
\hline MA0114.2 & HNF4A & 9.23257 & 0.8577651 & ABAT & 1739 & 1753 & - & GGGGACCCTGACCCT \\
\hline PB0134.1 & HNF4A & 11.0354 & 0.84987225 & ABAT & 1865 & 1880 & - & GGGCAGAGTCCAGCCT \\
\hline MA0114.1 & HNF4A & 12.9231 & 0.92296302 & ABAT & 1869 & 1881 & - & GGGGCAGAGTCCA \\
\hline MA0114.2 & HNF4A & 16.6494 & 0.95648952 & ABAT & 1868 & 1882 & + & CTGGACTCTGCCCCC \\
\hline
\end{tabular}

\begin{tabular}{|c|l|l|l|l|r|r|r|l|}
\hline Matrix ID & \multicolumn{1}{|c|}{ Name } & \multicolumn{1}{|c|}{ Score } & \multicolumn{1}{|c|}{ Relative score } & \multicolumn{1}{c|}{ Sequence ID } & \multicolumn{1}{c|}{ Start } & \multicolumn{1}{c|}{ End } & Strand & \multicolumn{1}{c|}{ Predicted sequence } \\
\hline MA0114.1 & HNF4A & 12.4961 & 0.91270087 & ALDH6A1 & 170 & 182 & + & AGATCAAAGGGTC \\
\hline MA0114.2 & HNF4A & 10.3867 & 0.87312702 & ALDH6A2 & 169 & 183 & - & TGACCCTTGATCTA \\
\hline MA0114.1 & HNF4A & 8.73947 & 0.8224064 & ALDH6A3 & 172 & 188 & + & ATCAAAGGGTCAACTTA \\
\hline MA0114.1 & HNF4A & 9.72313 & 0.84604983 & ALDH6A4 & 239 & 251 & - & AGTAGAAAGATCA \\
\hline MA0114.2 & HNF4A & 5.8903 & 0.81327632 & ALDH6A5 & 238 & 252 & + & GTGATCTTCTACTG \\
\hline
\end{tabular}

Fig. 7 Identification candidate transcription factor related to the differential ABAT and ALDH6A1 expression. a UALCAN revealed significant positive correlation between ABAT and ALDH6A1 in TCGA-KIRC samples. b LinkedOmics revealed positive correlation between HNF4A and ABAT or ALDH6A1 in TCGA-KIRC samples. Pearson correlation coefficient and corresponding $p$-values are shown. c Detailed information of HNF4A binding matrix. $\mathbf{d}$ Binding sites of HNF4A on ABAT and ALDH6A1 promoter 




with metastasis risk and prognosis in hepatocellular carcinoma (HCC) [29]. Both of them are down-regulated in HCC [30,31]. Our study identified that loss of ABAT and ALDH6A1 contributes to ccRCC tumor growth. Although the specific mechanisms of ABAT and ALDH6A1 in glutamate metabolism, glutathione GSH/GSSG determination, glucose uptake, and oxygen consumption should be determined in future research, our findings suggest that ccRCC patients might benefit from their influence on amino acid metabolism.

HNF4A inhibits proliferation in the stomach [32], colon [33] and kidney [27]. High expression of HNF4A leads to decreased growth of cancer cells. HNF4Amediated inhibition of cell proliferation involves 
multifold mechanisms, including miRNA regulation and epigenetic repression of oncogenes, as shown using tissue-specific conditional knockout mice and knock-in studies, and significant cross talk with other cell cycle regulators including $\mathrm{c}-\mathrm{Myc}$ and cyclin D1 [34]. The results of this study show that ABAT and ALDH6A1 are directly regulated by HNF4A, indicating that HNF4A suppresses ccRCC progression, at least in part, via the regulation of metabolic enzyme gene expression. Of cause, ABAT and ALDH6A1 may also be regulated by any microRNAs. In a future study, the expression levels of the related microRNAs need to be detected.

\section{Conclusion}

ABAT and ALDH6A1 expression is significantly downregulated in ccRCC tissues. Overexpression of ABAT or ALDH6A1 reduced cell proliferation and migration and impaired oncologic metabolism of renal cancer cells. Additionally, transcriptional factor HNF4A could be a potential mechanism affecting ABAT and ALDH6A1 expression.

\section{Supplementary information}

Supplementary information accompanies this paper at https://doi. org/10.1186/s12967-020-02268-1.

Additional file 1. Additional tables.

\begin{abstract}
Abbreviations
cCRCC: Clear cell renal cell carcinoma; ChIP: Chromatin immunoprecipitation; DEGs: Differentially expressed genes; DMEM: Dulbecco's modified Eagles medium; GEO: Gene Expression Omnibus; GSEA: Gene set enrichment analysis; HRP: Horseradish peroxidase; KEGG: Kyoto Encyclopedia of Genes and Genomes; mTOR: Mammalian target of rapamycin; NADPH: Nicotinamide adenine dinucleotide phosphate; RT-QPCR: Reverse transcription-quantitative polymerase chain reaction; TCGA: The Cancer Genome Atlas; TKI: Tyrosine kinase inhibitors; WST: Water-soluble tetrazolium salt.
\end{abstract}

\section{Acknowledgements}

The authors are grateful to the TCGA and GEO database for providing highquality data.

\section{Authors' contributions}

$J \mathrm{~L}$ and SJC designed the experiments. ZC, HZ, HYD, LZ, YZ, JW, HHZ and QC performed the experiments. JL, SLW and SSC provided the patient samples. $\mathrm{J}$ and $\mathrm{HZ}$ analyzed the data. $J \mathrm{~L}$ wrote the manuscript. All authors read and approved the final manuscript.

\section{Funding}

This work was supported by National Natural Science Foundation of China (Grant Number: 81570748), Science and Technology Innovation Joint Fund of Fujian Province (Grant Number: 2018Y9115), Natural Science Foundation of Fujian Province (Grant Numbers: 2018J01345, 2017XQ1194, and 2019J01528), Administration of Traditional Chinese Medicine of Sichuan Province (Grant Number: 2018JC035), Science \& Technology Department of Sichuan Province Applied Basic Research Program (Grant Number: 2018JY0368), and Outstanding Youth Funds of the 900 Hospital of the Joint Logistics Team (Grant Number: 2016Q04).

\section{Availability of data and materials}

The datasets supporting the conclusions of this article are available in the Xena browser (https://xenabrowser.net/) repository.

\section{Ethics approval and consent to participate}

The use of human tissues was approved by the Fuzhou General Hospital IRB, (Fuzhou, China), with written consent (2013-017).

\section{Consent for publication}

Not applicable.

\section{Competing interests}

The authors declare that they have no competing interests.

\section{Author details}

${ }^{1}$ Fujian Provincial Key Laboratory of Transplant Biology, Fuzhou General Clinical College, Fujian Medical University, Fuzhou 350025, China. ${ }^{2}$ Fujian Provincial Key Laboratory of Transplant Biology, Dongfang Hospital (900 Hospital of the Joint Logistics Team), Xiamen University, Fuzhou 350025, China. ${ }^{3}$ Department of Urology, 900 Hospital of the Joint Logistics Team, Fuzhou 350025, Fujian, China. ${ }^{4}$ Department of Urology, Second Affiliated Hospital of Chengdu Medical College (China National Nuclear Corporation 416 Hospital), Chengdu 610051, China.

Received: 6 December 2019 Accepted: 14 February 2020

Published online: 24 February 2020

\section{References}

1. Ljungberg B, Bensalah K, Canfield S, Dabestani S, Hofmann F, Hora M, et al. EAU guidelines on renal cell carcinoma: 2014 update. Eur Urol. 2015;67:913-24.

2. Krabbe LM, Haddad AQ, Westerman ME, Margulis V. Surgical management of metastatic renal cell carcinoma in the era of targeted therapies. World J Urol. 2014;32:615-22.

3. Jonasch E. Incorporating new systemic therapies in kidney cancer treatment. J Natl Compr Canc Netw. 2017;15:703-5.

4. Coller HA. Is cancer a metabolic disease? Am J Pathol. 2014;184:4-17.

5. Phan LM, Yeung SC, Lee MH. Cancer metabolic reprogramming: importance, main features, and potentials for precise targeted anti-cancer therapies. Cancer Biol Med. 2014;11:1-19.

6. Hakimi AA, Reznik E, Lee CH, Creighton CJ, Brannon AR, Luna A, et al. An integrated metabolic atlas of clear cell renal cell carcinoma. Cancer Cell. 2016;29:104-16.

7. Cancer Genome Atlas Research N. Comprehensive molecular characterization of clear cell renal cell carcinoma. Nature. 2013;499:43-9.

8. Sanchez DJ, Simon MC. Genetic and metabolic hallmarks of clear cell renal cell carcinoma. Biochim Biophys Acta Rev Cancer. 2018;1870:23-31.

9. Parviz M, Vogel K, Gibson KM, Pearl PL. Disorders of GABA metabolism: SSADH and GABA-transaminase deficiencies. J Pediatr Epilepsy. 2014;3:217-27.

10. Sass JO, Walter M, Shield JP, Atherton AM, Garg U, Scott D, et al. 3-Hydroxyisobutyrate aciduria and mutations in the ALDH6A1 gene coding for methylmalonate semialdehyde dehydrogenase. J Inherit Metab Dis. 2012;35:437-42.

11. Zaravinos A, Pieri M, Mourmouras N, Anastasiadou N, Zouvani I, Delakas D, et al. Altered metabolic pathways in clear cell renal cell carcinoma: a meta-analysis and validation study focused on the deregulated genes and their associated networks. Oncoscience. 2014;1:117-31.

12. Chen B, Jiao Z, Yin X, Qian Z, Gu J, Sun H. Novel insights into biomarkers associated with renal cell carcinoma. Oncol Lett. 2018;16:83-90.

13. Zhang $B$, Wu Q, Wang $Z, X u R, H u X$, Sun $Y$, et al. The promising novel biomarkers and candidate small molecule drugs in kidney renal clear cell carcinoma: evidence from bioinformatics analysis of high-throughput data. Mol Genet Genomic Med. 2019;7:e607.

14. Beroukhim R, Brunet JP, Di Napoli A, Mertz KD, Seeley A, Pires MM, et al. Patterns of gene expression and copy-number alterations in von-hippel lindau disease-associated and sporadic clear cell carcinoma of the kidney. Cancer Res. 2009;69:4674-81. 
15. Gumz ML, Zou H, Kreinest PA, Childs AC, Belmonte LS, LeGrand SN, et al. Secreted frizzled-related protein 1 loss contributes to tumor phenotype of clear cell renal cell carcinoma. Clin Cancer Res. 2007;13:4740-9.

16. Jones J, Otu H, Spentzos D, Kolia S, Inan M, Beecken WD, et al. Gene signatures of progression and metastasis in renal cell cancer. Clin Cancer Res. 2005;11:5730-9.

17. Lenburg ME, Liou LS, Gerry NP, Frampton GM, Cohen HT, Christman MF Previously unidentified changes in renal cell carcinoma gene expression identified by parametric analysis of microarray data. BMC Cancer. 2003;3:31.

18. Barrett T, Troup DB, Wilhite SE, Ledoux P, Rudnev D, Evangelista C, et al. NCBI GEO: archive for high-throughput functional genomic data. Nucleic Acids Res. 2009;37:D885-90.

19. Tomczak K, Czerwinska P, Wiznerowicz M. The Cancer Genome Atlas (TCGA): an immeasurable source of knowledge. Contemp Oncol (Pozn). 2015;19:A68-77.

20. Zhou Y, Zhou B, Pache L, Chang M, Khodabakhshi AH, Tanaseichuk O, et al. Metascape provides a biologist-oriented resource for the analysis of systems-level datasets. Nat Commun. 2019;10:1523.

21. Vasaikar SV, Straub P, Wang J, Zhang B. LinkedOmics: analyzing multiomics data within and across 32 cancer types. Nucleic Acids Res. 2018;46:D956-63.

22. Chandrashekar DS, Bashel B, Balasubramanya SAH, Creighton CJ, Ponce-Rodriguez I, Chakravarthi B, et al. UALCAN: a portal for facilitating tumor subgroup gene expression and survival analyses. Neoplasia. 2017;19:649-58.

23. Livak KJ, Schmittgen TD. Analysis of relative gene expression data using real-time quantitative PCR and the 2(-Delta Delta C(T)) Method. Methods. 2001;25:402-8.

24. Tang Y, Geng Y, Luo J, Shen W, Zhu W, Meng C, et al. Downregulation of ubiquitin inhibits the proliferation and radioresistance of non-small cell lung cancer cells in vitro and in vivo. Sci Rep. 2015;5:9476.

25. Netea-Maier RT, Smit JWA, Netea MG. Metabolic changes in tumor cells and tumor-associated macrophages: a mutual relationship. Cancer Lett. 2018;413:102-9.
26. Sel S, Ebert T, Ryffel GU, Drewes T. Human renal cell carcinogenesis is accompanied by a coordinate loss of the tissue specific transcription factors HNF4 alpha and HNF1 alpha. Cancer Lett. 1996;101:205-10.

27. Grigo K, Wirsing A, Lucas B, Klein-Hitpass L, Ryffel GU. HNF4 alpha orchestrates a set of 14 genes to down-regulate cell proliferation in kidney cells. Biol Chem. 2008;389:179-87.

28. Chen X, Cao Q, Liao R, Wu X, Xun S, Huang J, et al. Loss of ABAT-mediated GABAergic system promotes basal-like breast cancer progression by activating $\mathrm{Ca}(2+)-N F A T 1$ Axis. Theranostics. 2019;9:34-47.

29. Chen P, Wang F, Feng J, Zhou R, Chang Y, Liu J, et al. Co-expression network analysis identified six hub genes in association with metastasis risk and prognosis in hepatocellular carcinoma. Oncotarget. 2017;8:48948-58.

30. Reis H, Padden J, Ahrens M, Putter C, Bertram S, Pott LL, et al. Differential proteomic and tissue expression analyses identify valuable diagnostic biomarkers of hepatocellular differentiation and hepatoid adenocarcinomas. Pathology. 2015;47:543-50.

31. Liu Y, Zhu X, Zhu J, Liao S, Tang Q, Liu K, et al. Identification of differential expression of genes in hepatocellular carcinoma by suppression subtractive hybridization combined cDNA microarray. Oncol Rep. 2007:18:943-51.

32. Chang HR, Nam S, Kook MC, Kim KT, Liu X, Yao H, et al. HNF4alpha is a therapeutic target that links AMPK to WNT signalling in early-stage gastric cancer. Gut. 2016;65:19-32

33. Chellappa K, Deol P, Evans JR, Vuong LM, Chen G, Briancon N, et al. Opposing roles of nuclear receptor HNF4alpha isoforms in colitis and colitis-associated colon cancer. Elife. 2016;5:e10903.

34. Walesky C, Apte U. Role of hepatocyte nuclear factor 4alpha (HNF4alpha) in cell proliferation and cancer. Gene Expr. 2015;16:101-8.

\section{Publisher's Note}

Springer Nature remains neutral with regard to jurisdictional claims in published maps and institutional affiliations.
Ready to submit your research? Choose BMC and benefit from:

- fast, convenient online submission

- thorough peer review by experienced researchers in your field

- rapid publication on acceptance

- support for research data, including large and complex data types

- gold Open Access which fosters wider collaboration and increased citations

- maximum visibility for your research: over $100 \mathrm{M}$ website views per year

At BMC, research is always in progress.

Learn more biomedcentral.com/submissions 